Media Publikasi Promosi Kesehatan Indonesia The Indonesian Journal of Health Promotion

\title{
Gambaran Pengetahuan Dan Sikap Remaja Putri Kelas VII Tentang Menstruasi Di SMPN 2 Kapala Pitu Tahun 2018
}

\author{
Description of VII Class Knowledge and Attitudes of Young Women about \\ Menstruation in Senior High School 2 Kapala Pitu in 2018
}

\author{
Albertin Rapa \\ Akademi Kebidanan Sinar Kasih Toraja \\ Email : alberthinakbidsinarkasih@gmail.com
}

\begin{abstract}
Abstrak
Latar Belakang penulisan karya ilmiah Sebagian remaja sudah mengalami kematangan organ reproduksi dan dapat berfungsi atau bereproduksi, namun secara sosial dan mental mereka belum dewasa. Remaja akan mengalami banyak masalah jika pendidikan dan pengasuhan seksualitas dan reproduksinya terabaikan. Tujuan Penelitian adalah untuk mengetahui gambaran pengetahuan dan sikap remaja putri kelas VII tentang menstruasi di SMPN 2 KapalaPitu Kec. KapalaPitu, Kab. Toraja Utara Tahun 2018. Metode Penelitian yang digunakan adalah desain penelitian deskriptif dengan menggunakan tekhnik Non Probality Sampling dengan metode Purposive Sampling dengan jumlah 46 sampel. Data yang digunakan dalam penelitian ini adalah data primer, dengan variable di teliti adalah pengetahuan dan sikap siswa. Hasil Penelitian menunjukkan bahwa dari 46 siswi yang menjadi responden penelitian, terdapat $10(21,74 \%)$ siswi yang pengetahuan kurang, $26(56,52 \%)$ siswi yang pengetahuan cukup dan $10(21,74 \%)$ siswi yang pengetahuan baik. Dan dari 46 siswi yang menjadi responden penelitian, terdapat 13 (28,26\%) siswi yang bersikap negatif dan 33 (71,74\%) siswi yang bersikap positif. Kesimpulan dan Saran dari penelitian ini adalah masih terdapat siswi di SMPN 2 KapalaPitu yang berpengetahuan kurang dan bersikap negatif tentang menstruasi sehingga diharapkan kepada Kepala Sekolah dan Guru di sekolah untuk bekerjasama dengan tenaga kesehatan agar dapat memberikan penyuluhan kesehatan khususnya tentang menstruasi.
\end{abstract}

Kata Kunci : Pengetahuan, sikap, menstruasi

\begin{abstract}
Background of scientific writing Some teenagers have experienced reproductive organs maturity and can function or reproduce, but socially and mentally they are not yet mature. Teenagers will experience many problems if their education and care for sexuality and reproduction is neglected. The aim of the study was to describe the knowledge and attitudes of seventh grade girls about menstruation at Kapala Pitu 2 Public Middle School Kapala Pitu Subdistrict, North Toraja Regency in 2018. The research method used was descriptive research design using Non Probality Sampling techniques with Purposive Sampling methods with a number of 46 samples. The data used in this study are primary data, with the variables examined are the students' knowledge and attitudes. The results showed that of the 46 female students who were the respondents of the study, there were 10 (21.74\%) students who lacked knowledge, 26 (56.52\%) students who had sufficient knowledge and 10 (21.74\%) students who had good knowledge. And of the 46 female students who were respondents to the study, there were 13 (28.26\%) female students who were negative and 33 (71.74\%) students who were positive. Conclusions and Suggestions from this study is that there are still students at KapalaPitu 2 Junior High School who are less knowledgeable and negative about menstruation so it is expected that the Principal and Teachers in the school work together with health workers to be able to provide health education especially about menstruation.
\end{abstract}

Keywords: Knowledge, attitude, menstruation 


\section{PENDAHULUAN}

Kesehatan reproduksi yang ditetapkan dalam Konferensi Internasional Kependudukan dan Pembangunan (International on Population and Development/ICPD) adalah keadaan sejahtera fisik, mental dan sosial yang utuh; bukan hanya tidak adanya penyakit atau kelemahan, tetapi dalam segala hal yang berhubungan dengan sistem reproduksi dan fungsi serta proses-prosesnya [1].

Pubertas merupakan masa awal pematangan seksual, yakni suatu periode dimana seorang anak mengalami perubahan fisik, hormonal dan seksual serta mampu melakukan proses reproduksi. Hal ini ditandai dengan mulainya remaja putri mengalami menstruasi pertama (menarche). Menstruasi merupakan proses pelepasan dinding rahim (endometrium) yang disertai dengan perdarahan dan terjadi secara berulang setiap bulan kecuali pada saat kehamilan [2].

Badan Kesehatan Dunia (WHO) telah mengkompilasi masalah kesehatan reproduksi remaja yang terjadi diseluruh dunia, yang dapat menjadi bahan pembanding untuk masalah yang sama di Indonesia [1]. Sebagian remaja sudah mengalami kematangan organ reproduksi dan dapat berfungsi atau bereproduksi, namun secara sosial dan mental mereka belum dewasa. Remaja akan mengalami banyak masalah jika pendidikan dan pengasuhan seksualitas dan reprodusinya terabaikan [3].

Dari hasil penelitian yang dilakukan oleh Badan Kesehatan Keluarga Berencana Nasional (BKKBN) tahun 2013, menyebutkan sebanyak 4,38\% remaja usia 10-14 tahun telah melakukan aktivitas seks bebas, sedang remaja usia 14-19 tahun sebanyak 41,8\%. Berdasarkan Survei Kesehatan Reproduksi Remaja Provinsi DIY oleh badan pemberdayaan Perempuan dan Masyarakat, sebesar 54,40\% dari remaja tidak mengetahui hubungan seks pertama kali bisa menyebabkan kehamilan [1].

Pada umumnya menstruasi pertama terjadi pada usia 10-16 tahun, tetapi rata-rata terjadi pada usia 12,5 tahun. Statistik menunjukkan bahwa usia menarche dipengaruhi oleh faktor keturunan, keadaan gizi dan kesehatan umum [4].

Di Indonesia, gangguan menstruasi seperti dismenorea pada remaja putri masih sering terjadi, dimana yang mengalami dismenorea sebagian besar 94,5\% mengalami nyeri ringan sedangkan yang mengalami nyeri sedang 3,5\% dan nyeri berat 2\% [5]. Dari hasil penelitian Nurmiah (2016), yang meneliti tentang pengetahuan dan sikap remaja putri terhadap gangguan menstruasi di SMKN 2 Makale, didapatkan bahwa dari 80 siswi yang menjadi responden penelitian, terdapat 40 (50 \%) siswi yang berpengetahuan baik, 31 (38,75\%) siswi yang berpengetahuan cukup, dan 9 (11,25\%) siswi yang berpengetahuan kurang. Dan terdapat 62 (77,5\%) siswi yang bersikap baik, dan 18 (22,5\%) yang bersikap kurang [5].

Berdasarkan latar belakang di atas, maka peneliti tertarik untuk meneliti tentang "Gambaran Pengetahuan dan Sikap Remaja Putri kelas VII Tentang Menstruasi di SMPN 2 Kapala Pitu Kec. Kapala Pitu, Kab. Toraja Utara Tahun 2018”.

\section{METODE}

Desain penelitian yang digunakan dalam penelitian ini adalah penelitian deskriptif untuk mengetahui gambaran pengetahuan dan sikap remaja putri kelas VII tentang Menstruasi di SMPN 2 Kapala Pitu Kec. Kapala Pitu Kab. Toraja Utara Tahun 2018. Populasi dalam penelitian ini adalah semua siswi di SMPN 2 Kapala Pitu yang berjumlah 131 siswi. Sampel dalam penelitian ini adalah sebagian dari siswi SMPN 2 Kapala Pitu yang berjumlah 46 siswi, yaitu siswi yang berada pada kelas V. 
HASIL

Hasil penelitian yang selengkapnya akan disajikan dalam bentuk tabel disertai penjelasan dari masingmasing tabel :

1. Distribusi Siswi Menurut Pengetahuan

Tabel 1. Distribusi Siswi Menurut Pengetahuan Di SMPN 2 Kapala Pitu Kec. Kapala Pitu Kab. Toraja Utara Tahun 2018

\begin{tabular}{ccc}
\hline Pengetahuan & n & \% \\
\hline Kurang & 10 & 21,74 \\
\hline Cukup & 26 & 56,52 \\
\hline Baik & 10 & 21,74 \\
\hline Jumlah & 46 & 100 \\
\hline
\end{tabular}

Sumber : Data Primer, 2018

Table 1 menunjukkan bahwa dari 46 siswi yang menjadi responden penelitian, terdapat 10 $(21,73 \%)$ siswi yang pengetahuan kurang, 26 (56,52\%) siswi yang pengetahuan cukup dan 10 (21,73\%) siswi yang pengetahuan baik.

2. Distribusi Siswi Menurut Pengetahuan

Tabel 2. Distribusi Siswi Menurut Sikap Di SMPN 2 Kapala Pitu Kec. Kapala Pitu Kab. Toraja Utara Tahun 2018

\begin{tabular}{ccc}
\hline Sikap & n & \% \\
\hline Negatif & 13 & 28,26 \\
\hline Positif & 33 & 71,74 \\
\hline Jumlah & 46 & 100 \\
\hline
\end{tabular}

Sumber : Data Primer, 2018

Table2 menunjukkan bahwa dari 46 siswi yang menjadi responden penelitian, terdapat 13 (28,26\%) siswi yang bersikap negatif dan 33 (71,74\%) siswi yang bersikap positif.

3. Distribusi Perbandingan Antara Pengetahuan Dan Sikap

Tabel 3 Distribusi Perbandingan Antara Pengetahuan dan Sikap Remaja Putri tentang Menstruasi Di SMPN 2 Kapala Pitu Kec. Kapala Pitu, Kab. Toraja Utara Tahun 2018

\begin{tabular}{|c|c|c|c|c|c|c|}
\hline \multirow{3}{*}{ Variabel } & \multicolumn{4}{|c|}{ Sikap } & \multirow{2}{*}{\multicolumn{2}{|c|}{ Jumlah }} \\
\hline & \multicolumn{2}{|c|}{ Negatif } & \multicolumn{2}{|c|}{ Positif } & & \\
\hline & $\mathbf{n}$ & $\%$ & $\mathbf{n}$ & $\%$ & $\mathbf{n}$ & $\%$ \\
\hline \multicolumn{7}{|l|}{ Pengetahuan } \\
\hline Kurang & 5 & $10,86 \%$ & 5 & $10,86 \%$ & 10 & $21,74 \%$ \\
\hline Cukup & 7 & $15,21 \%$ & 19 & $41,30 \%$ & 26 & $56,52 \%$ \\
\hline Baik & 1 & $2,17 \%$ & 9 & $19,56 \%$ & 10 & $21,74 \%$ \\
\hline Jumlah & 13 & $28,26 \%$ & 33 & $71,74 \%$ & 46 & $100 \%$ \\
\hline
\end{tabular}

Sumber : Data Primer, 2018

Table 3 menunjukkan bahwa dari 46 siswi yang menjadi responden penelitian, terdapat 10 
$(21,74 \%)$ siswi yang berpengetahuan kurang, 5 (10,86\%) siswi yang memiliki sikap negatif dan 5 $(10,86 \%)$ siswi yang memiliki sikap positif. 26 (56,52\%) siswi yang berpengetahuan cukup, 7 $(15,21 \%)$ siswi yang memiliki sikap negatif dan 19 (41,52\%) siswi yang memiliki sikap positif. 10 $(21,74 \%)$ siswi yang berpengetahuan baik, 1 (2,17\%) siswi yang memiliki sikap negatif dan 9 $(19,56 \%)$ siswi yang memiliki sikap positif.

\section{PEMBAHASAN}

1. Gambaran pengetahuan Siswi SMPN 2 Kapala Pitu Tentang Menstruasi Tahun 2018

Menurut Notoatmodjo pengetahuan adalah hasil penginderaan manusia atau hasil tahu seseorang terhadap objek melalui indera yang dimilikinya (mata, hidung, telinga dan sebagainya) [6]. Dengan sendirinya, pada waktu penginderaan sampai menghasilkan pengetahuan tersebut sangat dipengaruhi oleh intensitas perhatian dan persepsi terhadap objek. Sebagian besar pengetahuan seseorang diperoleh melalui indera pendengaran (telinga) dan indera penglihatan (mata).

Seiring dengan tumbuh dan berkembangnya seorang individu dari masa anak-anak sampai dewasa, individu memiliki tugas masing-masing pada setiap tahap perkembangannya. Tugas yang dimaksud pada setiap tahap perkembangan adalah setiap tahapan usia, individu tersebut mempunyai tujuan untuk mencapai suatu kepandaian, keterampilan, pengetahuan, sikap, dan fungsi tertentu sesuai dengan kebutuhan pribadi.

Distribusi Siswi Menurut Pengetahuan di SMPN 2 Kapala Pitu Tahun 2018 yaitu bahwa siswi yang memiliki pengetahuan baik sebanding dengan siswi yang memiliki pengetahuan kurang tentang menstruasi, sedangkan yang memiliki pengetahuan yang cukup tentang menstruasi relatif lebih banyak. Hal ini menunjukkan bahwa pengetahuan remaja putri di SMPN 2 Kapala Pitu tentang menstruasi masih tergolong sangat minim. Hal ini mungkin disebabkan karena kurangnya informasi yang didapatkan oleh remaja putri baik itu dari orang tua maupun dari tenaga-tenaga kesehatan. Penyebab lain yang memungkinkan siswi belum memiliki pengetahuan baik tentang menstruasi adalah karena kurangnya faktor pendukung seperti pengalaman, pendidikan dan penggunaan panca indera secara lengkap

Menurut Notoatmodjo bahwa seseorang dapat memperoleh pengetahuan dari informasi yang didapatkan baik melalui pendidikan formal maupun non formal atau informasi melalui penyuluhan, media cetak, dan lain-lain [6].

2. Gambaran Sikap Siswi SMPN 2 Kapala Pitu Tentang Menstruasi Tahun 2018

Gibson menjelaskan sikap sebagai perasaan positif dan negatif atau keadaan mental yang selalu disiapkan, dipelajari dan diatur melalui pengalaman yang memberikan pengaruh khusus pada responden seseorang terhadap orang, obyek ataupun keadaan. Sikap lebih merupakan determinan perilaku sebab, sikap berkaitan dengan persepsi, kepribadian dan motivasi [7].

Selain itu, menurut Sunaryo sikap merupakan kesiapan merespon yang sikapnya positif atau negatif terhadap suatu objek atau situasi secara konsisten. Dimana sikap positif adalah kecenderungan tindakan mendekati, menyenangi, mengharapkan objek tertentu dan memberikan dasar pada orang 
tersebut untuk membuat respon atau perilaku dalam cara tertentu yang dipilihnya [8].

Kutipan diatas menunjukan tidak ada kesenjangan antara teori dan hasil penelitian bahwa siswi di SMPN 2 Kapala Pitu lebih banyak bersikap positif tentang menstruasi. Sikap yang positif ini merupakan salah satu orientasi remaja dalam kehidupannya. Sikap yang positif ini merupakan kecenderungan tindakan mendekati, menyenangi, mengharapkan objek tertentu yang mungkin dapat mempertimbangkan segala sesuatu dalam berpendapat dan melihat sudut pandang yang baik dalam berasumsi.

Menurut peneliti, sikap positif yang dimiliki oleh remaja putri di SMPN 2 Kapala Pitu ini mungkin disebabkan karena remaja tersebut tidak setuju dengan pernyataan negatif yang tercantum dalam kuisioner dan responden mampu memilih dan menentukan pilihan positif yang sebaiknya diambil dan dianggap layak untuk menjadi sikap dalam menindaki pernyataan tersebut.

3. Gambaran Perbandingan Antara Pengetahuan dan Sikap Siswi SMPN 2 Kapala Pitu Tentang Menstruasi Tahun 2018

Menurut teori yang dikemukakan oleh Notoatmodjo yang menunjukkan arah hubungan negatif yang berarti bahwa semakin baik pengetahuan tidak diikuti dengan peningkatan dari sikap yang positif [6].

Hal ini sesuai dengan hasil penelitian yang dilakukan penulis, yakni tidak semua siswi yang berpengetahuan baik akan memiliki sikap yang positif pula tentang menstruasi. Begitupun sebaliknya bahwa tidak semua siswi yang berpengetahuan kurang akan memiliki sikap yang negatif tentang mesntruasi.

Hal ini bisa saja terjadi karena pengetahuan dan sikap yang diperoleh dari remaja putri di SMPN 2 Kapala Pitu berbeda-beda karena beberapa faktor seperti lingkungan keluarga dimana keluarga adalah faktor utama dalam pembentukan kepribadian. Jika dalam keluarga menstruasi tidak pernah dijelaskan, dibahas atau dianggap tabu maka seorang anak akan mencari jawaban diluar dari lingkungan keluarga dan tidak bisa dijamin kebenaran informasi yang akan didapatkannya.

Bagi remaja yang memiliki pengetahuan kurang tentang menstruasi, bisa saja hal itu disebabkan oleh rendahnya rasa ingin tau mereka terhadap sistem reproduksi mereka secara benar sehingga membuat mereka malas untuk mencari informasi yang benar tentang sistem reproduksi khususnya menstruasi [9]. Namun, sikap dalam mengatasinya bisa saja positif karena dipengaruhi oleh beberapa faktor lingkungan yang mendukung seperti lingkungan kesehatan, lingkungan keluarga yang pernah membahas atau memberikan pengetahuan tentang hal tersebut, melalui pemberitaan media massa mengenai kasus-kasus yang berhubungan dengan hal tersebut dan pergaulan sehari-hari yang bisa menjadi faktor pendukung responden untuk bersikap positif. Begitu juga sebaliknya, mungkin remaja mendapatkan pengetahuan yang baik tentang menstruasi namun sikap dalam mengatasinya bisa saja negative [10].

Jadi dapat disimpulkan, semakin baik pengetahuan remaja tentang menstruasi belum tentu remaja tersebut memiliki sikap yang positif. Begitu pula sebaliknya, kurangnya pengetahuan remaja 
tentang menstruasi belum tentu remaja tersebut memiiki sikap yang negatif pula.

\section{KESIMPULAN DAN SARAN}

Dapat disimpulkan bahwa sebagian besar siswi belum mempunyai pengetahuan dan pemahaman yang baik tentang menstruasi. Khususnya pengetahuan mengenai siklus menstruasi. Begitu juga dengan sikap dari hasil penelitian di atas didapatkan gambaran bahwa siswi di SMPN 2 Kapala Pitu lebih banyak bersikap positif tentang menstruasi

Diharapkan kepada Kepala Dinas Pendidikan Kabupaten Toraja Utara untuk mengadakan program pelayanan kesehatan peduli remaja dan media informasi tentang remaja dan menstruasi.

\section{DAFTAR PUSTAKA}

[1] T. P. Kurniawan, "Faktor-faktor yang Berpengaruh Terhadap Praktek Kesehatan Reproduksi Remaja Di SMA Negeri 1 Purbalingga Kabupaten Purbalingga." Program Pasca Sarjana Universitas Diponegoro, 2008.

[2] N. R. Benita, J. Dewantiningrum, and N. Maharani, "Pengaruh Penyuluhan Terhadap Tingkat Pengetahuan Kesehatan Reproduksi Pada Remaja Siswa SMP Kristen Gergaji." Fakultas Kedokteran, 2012.

[3] U. M. S. SYARAT, M. G. S. S. SATU, M. O. H. A. FAWZI, and A.-A. ASY-SYAKHSIYYAH, "BATAS MINIMAL USIA PERKAWINAN MENURUT UNDANG-UNDANG NOMOR 1 TAHUN 1974 TENTANG PERKAWINAN DALAM PERSPEKTIF HUKUM ISLAM DAN KESEHATAN REPRODUKSI."

[4] D. Kasdu, Solusi problem wanita dewasa. Niaga Swadaya, 2005.

[5] D. Trimayasari and K. Kuswandi, "Hubungan usia menarche dan status gizi siswi SMP kelas 2 dengan kejadian dismenore," J. Obs. Sci., vol. 2, no. 2, pp. 195-216, 2015.

[6] S. Notoatmodjo, Pengantar Pendidikan Kesehatan dan Ilmu Perilaku Kesehatan. Yogyakarta: Andi of Set, 2003.

[7] A. N. Jatmiko, "Pengaruh Sikap Wajib Pajak pada Pelaksanaan Sanksi Denda, Pelayanan Fiskus dan Kesadaran Perpajakan terhadap Kepatuhan Wajib Pajak (Studi Empiris terhadap Wajib Pajak Orang Pribadi di Kota Semarang)." Program Pasca Sarjana Universitas Diponegoro, 2006.

[8] N. F. P. Putri, "Faktor-Faktor yang Berhubungan dengan Penggunaan Pemanis Sintetis Siklamat Berlebih pada Pangan Jajanan Anak Sekolah (PJAS) di Sekolah Dasar Negeri Wilayah Kelurahan Pondok Benda, Pamulang Barat dan Pamulang Timur Tahun 2015," 2015.

[9] P. Adisti, Personality plus for teens. Pustaka Grhatama, 2010.

[10] T. Hakim, Belajar secara efektif. Niaga Swadaya, 2005. 